\title{
CONSTRUINDO A AVALIAÇÃO INSTITUCIONAL NA UFPR
}

Valdo José Cavallet* Zaki Akel Sobrinho**

" a avaliação institucional começa muito antes de que esteja pronto o seu desenho, estejam elaborados os seus instrumentos e se levantem os primeiros dados da realidade a ser avaliada. Ela principia pela decisão da instituição, não importa que no começo seja somente através de um grupo pequeno, em geral da administração superior... o mais importante é que aos poucos uma parcela considerável da comunidade.... assuma esse empreen dimento como essen cial à melhoria da instituição" (Dias Sobrinho,1997)

\section{Resumo}

O presente texto tem como objetivo familiarizar o leitor com os fundamentos da retomada do processo de Avaliação Institucional na Universidade Federal do Paraná. Sendo a Avaliação um dos projetos estratégicos para a construção de um modelo alternativo de gestão, partimos de um amplo movimento de reflexão, que nos permitiu o autoconhecimento. A partir daí retomamos a visão histórica do processo desenvolvido em nossa universidade desde 1987, buscando entender o presente à luz da sua construção espacial e temporal, o que nos possibilitará apontar para o futuro de uma universidade na qual as diferenças não representam problemas, mas uma contribuição para um ambiente pluralista,com convivência democrática e sem lugar para a exclusão.

Palavras-chave: Avaliação Institucional, Universidade, Gestão Educacional, Educação Superior e Políticas Públicas.

\section{Résumé:}

Ce texte propose de rapprocher le lecteur des fondements de la reprise du processus d'Évaluation Institutionnelle dans l'Université Fédérale du Paraná. Dans la mesure que l'évaluation est vue comme un des projets stratétigiques

* Professor / Pesquisador do PPGE da UFPR.

Email: cavallet@ufpr.br

** Professor / Pesquisador do PPGA - CEPPAD/UFPR.

Email: zakiakel@ufpr.br 
pour la construction d'un modèle alternatif de gestion, nous entamons un fort mouvement de réflexion qui nous permettrat d'avoir l'auto-connaissance. À partir de ce mouvement de réflexion, nous reprenons la vision historique du processus déjà développé dans l'UFP depuis 1987, en essayant de comprendre le present à la lumière d'une construction spaciale et temporelle, ce que rendra possible cerner l'avenir de l'université dans laquelle les diférences ne representent pas de prbolèmes, mais se constituent dans une contribution pour un milieu pluriel, où les gens vivent démocratiquement et où il n' y a pas de place pour l'exclusion.

Mots-clés: Évaluation institutionnelle, Université, Gestion Éducative, Politiques Publiques.

\section{Apresentação}

Ao colocarmos o Projeto de Avaliação Institucional como um dos quatro projetos estratégicos da Gestão 2002-2006, estamos sinalizando para a importância que atribuímos a essa questão no processo de construção coletiva de um projeto alternativo de gestão para a UFPR, compromisso que esta gestão, liderada pelo Reitor Prof. Dr. Carlos Augusto Moreira Júnior e pelo Vice Reitor Prof. Dr. Aldair Tarcisio Rizzi, assumiu com a comunidade universitária, que o referendou nas urnas no final de 2001.

Em Carta à Comunidade, nossos dirigentes assim se expressavam sobre a necessidade de unir os esforços "para construir uma universidade onde as diferenças não representem problemas, mas uma contribuição para um ambiente pluralista, no qual haja convivência democrática, sem lugar para a exclusão". Só assim, com liberdade de pensamento, com rigor científico e um profundo autoconhecimento, a UFPR, nos seus 90 anos de existência, será capaz de reconquistar perante a sociedade paranaense e brasileira a sua condição de instituição que se destaca em várias áreas exercendo papel de referência e liderança no cenário local e nacional.

Tendo presente, como nos ensina Dias Sobrinho (1997), que "a universidade não é simplesmente o seu produto aparente e quantificável, mas também e, sobretudo, a história de seu processo de construção", fomos buscar na história, no seu permanente movimento, os fundamentos para situar 0 olhar sobre nossa universidade hoje.

Com o objetivo de colocar em evidência um dos nossos princípios fundamentais - a participação - buscamos confrontar nossas percepções com as teorias e práticas universitárias presentes no debate contemporâneo, ao mesmo tempo em que buscávamos nos registros documentais um conhecimento mais aprofundado sobre a trajetória do processo de institucionalização da avaliação no âmbito da Universidade Federal do Paraná. 
I- A RETOMADA DA AUTO-AVALIAÇÃO: da necessidade de compreender a realidade institucional no seu a contecendo

O intenso movimento de reflexão coletiva que nos envolveu nos primeiros meses do ano e que nos permitiu a construção de um amplo diagnóstico e de uma proposta de planejamento estratégico necessitava agora de um confronto com a avaliação já sistematizada, em gestões anteriores, para que novamente retomássemos o processo.

A auto-avaliação que caracterizou nosso movimento de reflexão e diagnóstico permitiu o registro das manifestações mais significativas da comunidade, na compreensão do momento presente de nossa Universidade.

Os diferentes grupos, o enorme contingente de professores, servidores e alunos que se debruçaram sobre as questões "com visão crítica, reflexiva e personalidade política" deixavam claro que com espírito participativo e democrático estavam efetivamente engajados na construção de um conhecimento, que mais que alimentar a crítica fornecesse os indicadores para a etapa de construção do novo projeto político-institucional para a UFPR.

A luz dos conhecimentos históricos, era necessário que canalizássemos toda essa energia e concentrássemos os esforços na "construção efetiva de ...um projeto de... Universidade pública, gratuita, de qualidade e com compromisso social".

Certamente uma perspectiva nova que implica em mudança cultural e que para tornar realidade o MUDA UFPR, necessita de uma estratégia metodológica que associe Planejamento Estratégico e Pedagógico,

como processos integrados que não podem prescindir da avaliação como movimento em busca da qualidade almejada. Uma qualidade que não está balizada apenas pela idéia reducionista que a quer como sinônimo de quantidade, portanto, restrita a ótica econômica e / ou gerencial (ZAINKO,1999).

O resgate histórico vai nos mostrar que como uma questão permanentemente associada a um referencial de qualidade para o ensino de graduação (atividade que ao longo dos tempos se constituiu no cerne das atividades típicas da universidade) a avaliação, nos diferentes modos de compreensão, fez parte das lutas do Movimento de Docentes das Universidades Brasileiras desde a década de 60 .

Em nossa Universidade não foi diferente. As discussões aconteciam, a luta pela qualidade sempre foi um princípio balizador das discussões, que ganharam força na década de 80, mais especificamente em 1988, quando formalmente a administração superior da Universidade institui a primeira comissão de avaliação institucional da UFPR. Este fato marca um momento polí- 
tico importante, não só porque experimentávamos a construção de um projeto de universidade, sob a orientação de uma administração escolhida pela comunidade e oriunda do Movimento docente, mas também porque buscávamos pela institucionalização superar a visão fragmentada de ações isoladas de caráter avaliativo que eram desenvolvidas em várias unidades da instituição. A sistematização das várias experiências em andamento mais que um desafio, passavam a representar de maneira inequívoca a decisão política de "intervenção" no fazer universitário, adaptando o papel e as funções da universidade a um novo tempo historicamente determinado.

A política de avaliação como meta inicia-se pela disseminação de informações sobre conceitos, diretrizes e experiências de avaliação universitárias publicadas sob a forma de Cadernos de Avaliação.

Com a proposição de um Programa de Avaliação denominado PROAV, a questão, liderada pelo Fórum de Pró-Reitores de Graduação, presidido por representante de nossa Universidade, ganha força no âmbito do Ministério da Educação, mais especificamente na SESU, e tem início um novo movimento que iría culminar com a constituição de uma Comissão Nacional que elaborou o PAIUB- Programa de Avaliação Institucional das Universidades Brasileiras.

Durante praticamente três gestões administrativas (1986-90; 1990-94; 1994-98) as ações se desenvolveram num movimento crescente de valorização e se caracterizaram pela continuidade e expansão. Durante esse período o cerne principal foi o ensino de graduação, mas paulatinamente foram sendo agregadas novas visões não só nas áreas-fim, como também nas áreas-meio.

O auge do movimento se deu no período 1990-94, quando foram intensificadas as discussões, as publicações, a disseminação da experiência da UFPR, que passou a ser modelo, no que tange à avaliação do docente pelo discente, numa perspectiva integrada de avaliação da disciplina e com um bem montado programa de aperfeiçoamento docente e de avaliação da estrutura dos currículos dos cursos. Os resultados do processo constituem um acervo considerável de publicações (Cadernos, documentos, artigos científicos publicados em periódicos nacionais e internacionais, relatórios de pesquisas, etc.).

No período 1994-98, a UFPR leva sua experiência para o Grupo Montevideo e passa a coordenar o Núcleo de Evaluación Institucional, compartilhando com universidades argentinas, uruguaias, paraguaias, brasileiras, chilenas suas reflexões e os resultados de suas práticas.

É desse período a obtenção de uma Cátedra da UNESCO denominada de Cultura de Paz e que tendo a avaliação como base deveria ser a responsável pelo desencadear de um movimento latino-americano de superação das desigualdades sociais nos campos educacional, social, artístico, tecnológico e cultural. Lamentavelmente também é desse período o erro estratégico de suspensão do processo de avaliação do docente pelo discente (naquela época 
presente em toda universidade nos seus cursos de graduação semestrais e anuais). A justificativa da necessidade de aperfeiçoamento dos instrumentos era sustentada por uma concepção inadequada de avaliação que deixava de entendê-la como processo, como movimento, que quando se instala jamais pode ou deve ser interrompido, até porque historicamente esta é uma impossibilidade colocada pelo tempo que avança inexoravelmente.

O registro da trajetória da Avaliação Institucional na UFPR encontrase sistematizado no documento da série Avaliação Institucional denominado Avaliação Institucional na UFPR: a trajetória de uma década 1987-97, organizado pelas professoras Maria Amélia Sabbag Zainko e Maria Lúcia Accioly Teixeira Pinto.

A síntese que apresentamos a seguir tem como base aspectos históricos contidos no documento e permite de maneira mais segura a visualização das diversas etapas que integraram esta caminhada.

Colocamos em destaque, de maneira especial, às informações referentes à caracterização de cada período, porque tomaram como referência os documentos que registraram, a seu tempo, os diversos passos dados, como os planos de ação e relatórios de gestão administrativa, os planos e projetos de avaliação elaborados e os respectivos relatórios, assim como as publicações concernentes ao assunto editadas e divulgadas pela Universidade.

\section{II - Síntese do processo de avaliação na UFPR ${ }^{1}$}

\section{- 1987 - 1990 - A Fundamentação do Processo de Avaliação}

Ao criar em 1987 um grupo encarregado de elaborar projeto de melhoria da qualidade do ensino de graduação, habilitando a UFPR junto ao PADES/MEC - Programa de Apoio e Desenvolvimento do Ensino Superior, a então denominada PREP - Pró-Reitoria de Ensino e Pesquisa deu os passos iniciais para a sistematização de ações avaliativas que se desenvolviam no interior da Universidade e para a configuração de um projeto político-pedagógico que viesse a estabelecer uma efetiva relação entre Universidade e Sociedade.

O ano de 1988 representa um marco importante na institucionalização do processo de avaliação com a designação pela PREP da primeira Comissão de Avaliação da UFPR, incumbida de organizar e estimular o processo de avaliação no âmbito da instituição, tendo a graduação como eixo condutor. A fundamentação da proposta de avaliação e as diretrizes para o seu desenvolvimento acham-se publicadas no primeiro número da série "Cadernos de Avaliação" a qual veio a se constituir em importante canal de divulgação de todo o processo que se desencadeou. 
Tendo como objetivos gerais:

- trazer para o interior da Universidade os resultados do debate nacional sobre a avaliação;

- criar espaço necessário para o desencadeamento do processo de avaliação de forma sistemática;

- traçar, explicitar e debater diretrizes para a avaliação institucional.

Este período foi bastante rico em discussões e busca de envolvimento da comunidade e propiciou que fossem desenvolvidas como principais metas:

- delineamento das diretrizes básicas para a avaliação;

- promoção de encontros e seminários sobre avaliação;

- divulgação de documentos e textos sobre avaliação;

- edição de publicação específica - série Cadernos de Avaliação;

- estímulo, apoio e divulgação a experiências de avaliação de cursos.

\section{- 1990 - 1994 - A Institucionalização do Processo de Avaliação}

A inserção da avaliação institucional no Plano de Ação da Reitoria, gestão 1990-94, deu impulso às ações que vinham se desenvolvendo, confirmando que a via adotada para a institucionalização do processo de avaliação, ou seja, a que contemplava a graduação como fio condutor, representava a possibilidade de atingir uma proposta de caráter mais global, dado o efeito multiplicador a ser exercido em todas as instâncias.

Deste modo, a avaliação institucional entendida como condição para o desenvolvimento qualitativo do ensino superior passou a ser empreendida no período em questão sob a forma de processo envolvendo três aspectos estreitamente associados: o projeto pedagógico, a estrutura curricular e o desempenho acadêmico dos docentes. Sem representar prejuízo para as demais áreas do conjunto universitário, onde experiências vinham se concretizando, a ênfase no ensino de graduação demonstrou ser uma opção viável para 0 estabelecimento de uma cultura avaliativa que, aos poucos, se disseminava.

Em função da divulgação e participação em encontros nacionais, 0 processo de avaliação desenvolvido neste período na UFPR configurou-se como uma das referências significativas na área, o que veio a se constituir em oportunidades efetivas de intercâmbio com as demais instituições universitárias brasileiras, contribuindo para a consolidação da proposta nacional de avaliação. Tendo se feito presente, como um de seus membros, na composição da Comissão Nacional de Avaliação instituída pelo MEC, a UFPR participou da elaboração da referida proposta, explicitada em 1993 no documento "Avaliação das Universidades Brasileiras", base do PAIUB - Programa de Avaliação 
Institucional das Universidades Brasileiras, que veio a ser implantado a partir de 1994.

Os objetivos definidos e que nortearam as ações no período foram:

- avaliar o projeto pedagógico a partir da compreensão da necessidade de se redefinir a função social e científica da Universidade em termos de eficácia social de suas ações e eficiência de seu funcionamento enquanto estrutura voltada ao ensino, pesquisa e extensão;

- avaliar a estrutura curricular, diretamente associada ao binômio ensino-aprendizagem, contemplando programas, conteúdos, metodologia e condições em que ocorre a relação pedagógica;

- avaliar o desempenho acadêmico dos docentes tendo como eixo articulador a construção coletiva de um projeto de Universidade centrado na razão produtividade/competência enquanto busca de efetiva integração ensino/pesquisa/ extensão.

Tais objetivos delimitaram o alcance das seguintes metas:

- consolidação e expansão da avaliação dos cursos e reestruturação curricular, abrangendo as dimensões interna e externa da Universidade;

- avaliação do conjunto dos cursos noturnos sob a ótica da relação educação e trabalho;

- avaliação do docente pelo discente na perspectiva da avaliação das disciplinas, a partir de experimento piloto que se expandiu para todos os cursos;

- auto-avaliação docente como decorrência da análise do previsto/ realizado em relação aos Planos Individuais de Trabalho;

- avaliação do desempenho docente envolvendo atividades-fim e de administração, com vistas à progressão na carreira;

- avaliação da carga de trabalho docente mediante a análise dos planos departamentais e dados disponíveis no Departamento de Assuntos Acadêmicos;

- desenvolvimento de um sistema de avaliação da produtividade docente em ação conjunta e integrada entre as instâncias competentes (PróReitorias, Conselho de Ensino e Pesquisa e CPPD).

- avaliação do desempenho técnico-administrativo;

- avaliação da gestão financeira.

\section{- 1994 - 1996 - A Consolidação do Processo de Avaliação}

O desenvolvimento sistemático da avaliação, resultante do esforço despendido ao longo dos anos e a conscientização pela comunidade universi- 
tária da sua importância e necessidade, possibilitaram que se delineasse, a partir de 1994, um elenco de temas prioritários para a efetivação e consolidação do processo enquanto projeto global de avaliação em todas as instâncias. Deste modo, sempre centrada na graduação como seu pólo irradiador, a avaliação passou a abranger todos os aspectos da vida universitária tendo como pressuposto a interação entre planejamento institucional e avaliação, enquanto elementos orientadores da tomada de decisão.

A Comissão de Avaliação Institucional, redimensionada em sua composição e redefinida em suas atividades, foi elevada a uma posição supra próreitorias, vinculada ao gabinete da Reitoria, com a garantia do compromisso da administração superior da Universidade. Com o advento do PAIUB, a Comissão passou à elaboração e coordenação do Projeto de Avaliação Institucional da UFPR - biênio 94-95.

Os objetivos gerais estabelecidos para o período foram:

- intensificar a discussão com a comunidade universitária sensibilizando-a para uma participação mais efetiva no processo de avaliação;

- dar seqüência ao processo de avaliação do ensino de graduação na perspectiva de avaliação dos cursos, considerando os indicadores internos e os externos;

- consolidar o Banco de Dados sobre o ensino de graduação e 0 sistema de avaliação da produtividade docente, adequando as informações aos parâmetros estabelecidos pelo PAIUB;

- reorganizar a estrutura institucional para o planejamento, a implementação e o acompanhamento do projeto de avaliação institucional;

- adequar a metodologia em desenvolvimentos às exigências de um modelo nacional;

- descentralizar, no interior da Universidade, o controle e o acompanhamento das ações desenvolvidas em termos de avaliação dos docentes pelos discentes, avaliação da força de trabalho docente e do pessoal técnicoadministrativo, avaliação da produção acadêmica e avaliação da execução dos programas de gestão.

Neste período foram atingidas as seguintes metas:

- criação da estrutura institucional de avaliação pela recomposição e redefinição da Comissão de Avaliação Institucional;

- consolidação do diagnóstico institucional por meio da sistematização, em um único Banco de Dados, das informações existentes, possibilitando o estabelecimento de indicadores;

- divulgação e discussão dos resultados decorrentes das sistemáticas de avaliação desenvolvidas com vistas à retroalimentação contínua do 
processo de planejamento institucional por meio de diferentes estratégias (encontros, reuniões, fóruns, seminários, publicações);

- acompanhamento e controle das ações de avaliação institucional em desenvolvimento consentâneo com os programas institucionais da gestão 1994-98, intensificando e consolidando o processo avaliativo, compreendendo:

- caracterização geral dos cursos de graduação e sua clientela;

- reestruturação curricular;

das disciplinas;

- avaliação do docente pelo discente na perspectiva da avaliação

- auto-avaliação docente;

- articulação com as demais instâncias de avaliação da pós-graduação, extensão, recursos humanos e gestão financeira;

- avaliação do estágio probatório e progressões na carreira docente e técnico-administrativa;

- avaliação da relação da Universidade com a sociedade mediante atividades extensionistas;

- análise da força de trabalho docente e técnico-administrativo;

- análise da produção do conhecimento;

- análise dos custos das atividades gerais;

- análise da estrutura e dinâmica administrativas.

- implantação de medidas saneadoras a partir das necessidades detectadas pela avaliação institucional:

- incentivo à formação de grupos de estudo;

- promoção de assessoramento didático-pedagógico;

- criação do Fórum Permanente de Coordenadores de Cursos de Graduação;

- desenvolvimento de projeto na área dos cursos de licenciatura em articulação com o PROLICEN/MEC - Programa das Licenciaturas;

- desenvolvimento de projeto na área de laboratórios de ensino em articulação com o PROGRAD/MEC - Programa de Graduação.

\section{- 1996 - 1997 - A Expansão do Processo de Avaliação}

Dando seqüência ao processo avaliativo de caráter global, a UFPR apresentou em 1996 a sua demanda no âmbito da convocatória do PAIUB por meio do Projeto de Avaliação Institucional para o biênio 1996-97. A avaliação, associada ao planejamento institucional, constitui-se em instrumento catalisador de ações que visam ao desenvolvimento da instituição como um todo e, em 
especial, o redirecionamento do processo de formação em seus diferentes níveis. Os resultados até então obtidos apontam para a necessidade de aprofundamento em questões desafiadoras como o aperfeiçoamento das formas de ingresso na graduação e na pós-graduação bem como as condições de mobilidade e permanência do corpo discente.

Como integrante do AUGM - Associação de Universidades Grupo Montevideo, a UFPR passou a coordenar neste âmbito o Núcleo Disciplinar "Avaliação Institucional", abrindo perspectivas para o intercâmbio de experiências e possibilidades de realização da avaliação externa.

Os objetivos gerais do período foram:

- dar continuidade ao processo de avaliação do ensino de graduação na perspectiva da avaliação dos cursos, considerando os indicadores internos e externos;

- disponibilizar acesso ao Banco de Dados existente abrangendo informações sobre ensino de graduação, pós-graduação e sistema de avaliação da produtividade docente, conforme parâmetros estabelecidos pelo PAIUB e pelo Grupo Montevideo, com vistas a intercâmbio efetivo;

- dar consistência ao Sistema de Informações Gerenciais mediante a consolidação dos módulos: Sistema de Atividades Docentes (SAD), Sistema de Apuração de Custos (SAC), Sistema de Administração de Patrimônio (SAP), Sistema de Acompanhamento Acadêmico (SAA) e Sistema de Controle de Materiais (SCM);

- realizar a avaliação extema a partir de modelo experimental de avaliação das diferentes unidades.

As metas atingidas ou em desenvolvimento e documentadas foram:

- acompanhamento e avaliação dos resultados do Concurso Vestibular de 1996, envolvendo normas, procedimentos, conteúdos das provas, desempenho acadêmico dos aprovados, entrevistas com professores e alunos ingressantes;

- avaliação de cursos pormeio de projeto-piloto coordenado pelo Fórum Permanente de Coordenadores de Curso de Graduação, envolvendo 10 cursos, em desenvolvimento;

- avaliação de cursos no âmbito de seus Colegiados;

- avaliação do fluxo acadêmico na graduação envolvendo evasão, desligamento e tempo de permanência média do aluno no curso;

- avaliação do perfil do aluno de graduação, em integração com projeto nacional, em desenvolvimento;

- avaliação de disciplinas e docentes pelos discentes e divulgação das análises em publicação específica;

- proposta de avaliação das atividades desenvolvidas no âmbito do projeto dos cursos de licenciatura, em elaboração; 
- avaliação dos cursos de pós-graduação - mestrado e doutorado, a partir de levantamento e discussão dos indicadores referentes ao período 199195, com análise em elaboração;

- análise da evolução da política de concessão de bolsas de demanda social na pós-graduação, em elaboração;

- avaliação dos programas de bolsas de iniciação científica;

- avaliação da política de concessão e manutenção da dedicação exclusiva em relação ao desenvolvimento de projetos de pesquisa;

- avaliação das atividades de extensão - cursos, eventos, projetos, programas e divulgação por meio de publicação específica;

- avaliação do programa de bolsa-extensão;

- proposta de avaliação de atividades de extensão pela comunidade atendida, em elaboração;

- avaliação de desempenho em estágio probatório de docentes e técnicos-administrativos, totalizando 1171 servidores em 1996;

- avaliação de desempenho de servidores técnico-administrativos mediante projeto-piloto em desenvolvimento, envolvendo nesta etapa 388 servidores;

- avaliação do processo de alocação de vagas docentes, com modelo de alocação em discussão;

- avaliação do dimensionamento dos recursos humanos técnico-administrativos, em desenvolvimento;

- implantação e consolidação do Sistema de Atividades Docentes, através do RADOC - Relatório Anual de Atividades Docentes; do Sistema de Apuração de Custos - SAC e do Sistema de Administração de Patrimônio - SAP;

- consolidação do Banco de Dados e análise de consistência;

- avaliação e readequação dos laboratórios de ensino;

- avaliação e readequação do espaço físico para portadores de necessidades especiais;

- avaliação e manutenção da infra-estrutura em geral com ênfase na expansão da rede de informática e telefonia;

- implantação das diretrizes do Plano Diretor da UFPR quanto à melhoria e expansão dos espaços físicos a partir das necessidades detectadas;

- diagnóstico dos programas, projetos e atividades de avaliação em desenvolvimento na UFPR.

\section{Institucional}

- 1998 - 2002 - A interrupção do processo de Avaliação

Este período é caracterizado por uma mudança de orientação na 
gestão da UFPR. O relato da trajetória dos últimos 10 anos não foi considerado e ações ganharam novamente as características de ações isoladas e fragmentadas. Foi perdido com isto o elo de uma corrente que indicava um processo contínuo e aberto de autoconhecimento e um amplo campo para análises e estudos que, além de consolidar a riqueza de uma sistemática de avaliação em movimento, produzia elementos significativos para a redefinição de um projeto de desenvolvimento institucional, calcado em análises sistemáticas do cotidiano da vida universitária.

Como se fosse possível uma volta no tempo histórico passamos a contar novamente com posições superadas e características dos momentos iniciais como a resistência ao desenvolvimento da avaliação por parte da comunidade interna pelo temor de um possível caráter punitivo. Desaparece a motivação e quase que se torna natural cumprir as exigências de um diagnóstico meramente quantitativo.

A política encaminhada pela SESU/MEC exigia um posicionamento firme da comunidade universitária, que ao interromper o processo possibilitou que a lógica de orientação da avaliação institucional prevalecente fosse a da qualidade total.

Os estudiosos da questão têm alertado para o fato de que "a qualidade total é portadora de uma ideologia que não aceita o pluralismo de idéias, a liberdade e a autonomia de espírito necessárias à produção científica e cultural, à criação de bens simbólicos, além de materiais. Rejeitando a crítica e negando a transformação, essa qualidade total acaba mesmo é confirmando os valores e padrões que servem ao mercado..." ( DIAS SOBRINHO,1997)

Esta concepção muitas vezes não explicitada pela comunidade universitária busca direcionar com uma lógica que é própria do mercado, ações educacionais que possuem lógicas e interesses totalmente diferentes, principalmente porque a Educação Superior foi declarada pela UNESCO com bem público, portanto direito do cidadão.

\section{- 2002-2006 - A Avaliação Institucional como projeto estraté- gico de gestão}

Para a atual gestão da UFPR, a prática do planejamento entendido como processo permanente e necessariamente concebido com a efetiva participação da comunidade o vincula de modo indissociável à avaliação institucional. Ambos fazem parte de um mesmo continuum e se desenvolvem de forma articulada em todas as unidades da universidade.

Como projeto estratégico de gestão, a Avaliação Institucional atu- 
ará como eixo articulador das mudanças, perpassando todas as unidades fim e meios da Universidade.

Em sua fase inicial de retomada efetiva do processo buscará colocar em evidência o papel que a avaliação pode e deve desempenhar, enquanto instrumento de análise e de subsídios à tomada de decisões, bem como chamará a atenção para os desafios da educação superior, neste início de milênio. Assim,

é preciso considerar que no atual momento da história mundial onde 0 elemento essencial é a mudança de rumo do processo civilizatório, com reflexos sobre todos os domínios e condições das atividades da vida dos homens e da sociedade..., as universidades, como cérebros das nações, não podem se eximir de participar da construção de uma nova cultura, produzindo conhecimentos fundamentais para a compreensão do momento que se vive, adaptando-se aos novos tempos e, principalmente, assumindo por meio de suas atividades de ensino, pesquisa e extensão, de busca e reflexão permanentes, a sua capacidade de antecipar e influenciar as mudanças, orientando suas ações na direção de um desenvolvimento humano durável e solidário. (ZAINKO, 2000)

É chegado, pois, o momento de, em função de tão importantes desafios, as universidades se prepararem para rever de maneira adequada sua missão, de modo a estar em condições de responder às exigências da sociedade do conhecimento que requer saberes para a Educação do Futuro.

Se o século XX acabou por consagrar uma forma de desenvolvimento que, a cada dia, vai se tornando insustentável, é forçoso reconhecer que novas formas de solidariedade e responsabilidade se manifestam, estimulando a unidade da diversidade con tra as ten dên cias do pensamento único..." (CARVALHO,2000) e que como nos assegura Edgar Morin, baseado na teoria da complexidade, a educação do futuro deverá "estimular os educadores brasileiros.... a irem à luta ...garantindo às futuras gerações um mundo com mais beleza e sustentabilidade".(CARVALHO,2000).

Portanto, construir um projeto alternativo de gestão implica ter presente que o compromisso social e a qualidade que se requer da universidade pública e gratuita, hoje, exige de todos os que constroem no dia-a dia a prática universitária, um esforço de "diálogo criativo com as dúvidas e interrogações do nosso tempo"(Cunha, 2000) que nos levam a um repensar das funções-fim de ensino, pesquisa e extensão aproximando-as dos interesses e necessidades de uma sociedade que requer urgência na universalização da cidadania.

Dar seqüência ao nosso propósito comum, tendo a avaliação institucional como o eixo articulador da mudança, que não exclui outros como a qualidade de vida, o marketing institucional e o sistema de informação, no 
momento em que o Brasil prepara-se para redirecionar o rumo de suas políticas educacionais buscando um desenvolvimento humano e social, é a tarefadesafio que nós da comunidade da UFPR deveremos assumir, responsáveis que somos, como universidade pública e gratuita (a maior e mais antiga do Estado) pela liderança dos processos de reformas e mudanças que possam representar alternativas concretas de redução da exclusão e da marginalização sociais.

Neste sentido, as estratégias escolhidas de imediato envolvem o lançamento de nossa compreensão no Seminário Internacional de Avaliação Institucional da Educação Superior, em sua fase nacional a ser realizada nos dias 02 e 03 de dezembro, em parceria, na perspectiva do intercâmbio e do entendimento intercultural. Lançamento para a comunidade interna da UFPR dos Cadernos de Avaliação Institucional - Série Estudos- no dia 11 de dezembro e socialização com a comunidade paranaense no dia 19 de dezembro no Auditório da Reitoria, por ocasião da sessão magna de comemoração dos 90 anos de nossa Universidade.

Com a apresentação dos documentos com os quais estaremos fundamentando nossa prática no campo da Avaliação Institucional, na gestão 20022206, reafirmamos para a comunidade acadêmica e para a sociedade que 0 nosso entendimento da avaliação como processo estratégico de melhoria da qualidade da gestão está sustentado por algumas características essenciais, que segundo Dias Sobrinho são:

- o caráter de globalidade (deve envolver não só os cursos de graduação e pós-graduação, mas todas as funções do contexto da instituição possibilitando uma articulação entre estruturas pedagógicas e administrativas);

- a construção de um processo participativo e negociado;

- a função operatória e estruturante da avaliação (avaliação orientada para a tomada de decisões e a transformação da realidade, ao longo do processo);

- a sua função formativa;

- a legitimidade política e técnica do processo;

- a sua capacidade de estar adaptada a cada unidade da instituição;

- a articulação com as demandas do mundo da vida e do trabalho.

Com tal entendimento estamos ainda reafirmando que Planejamento e Avaliação Institucional exercem papel estratégico na construção de um modelo alternativo de gestão porque se constituem em processos integrados e permanentes de reflexão-ação que ultrapassam amplamente as iniciativas frag- 
mentadas e tópicas de avaliação que ocorrem todos os dias em uma universidade.

Construindo uma cultura de avaliação na qual a participação seja efetivamente a palavra-chave no processo de reconstrução e de resgate do papel da UFPR perante a sociedade local, regional e nacional, estamos a partir de uma visão de um passado de glórias, sedimentando um presente de compromisso social e apontando para um futuro no qual UFPR e comunidade estarão trilhando os caminhos possíveis de um desenvolvimento social harmônico.

\section{Nota}

1 A idéias centrais encontram-se mais detalhadas em ZAINKO et al., 1997.

\section{Referências}

CARVALHO, E. A Considerações sobre Os sete saberes necessários à Educação do Futuro. São Paulo: Cortez; Brasília: UNESCO, 2000.

COMISSÃO DE AVALIAÇÃO INSTITUCIONAL DA UFPR. Projeto de Avaliação Institucional. Curitiba: UFPR, 1994..

. Cadernos de Avaliação. Curitiba, n. 1 - 13, 1988 /1995.

CUNHA, C. Considerações sobre Os sete saberes necessários à Educação do Futuro. São Paulo: Cortez, 2000.

DIAS SOBRINHO, J. Avaliação Institucional: integração e ação integradora. Revista Avaliação: RAIES, Campinas, v.2, n. 2, p. 19-30, jun. 1997.

MORIN,E. Os sete saberes necessários à Educação do Futuro. São Paulo: Cortez; 2000.

UNIVERSIDADE FEDERAL DO PARANÁ. PAPUFPR Programa de Administração para a UFPR: Gestão:2002/2006, Curitiba, 2001.

ZAINKO, Maria Amélia S.et al. Avaliação Institucional na UFPR: trajetória de um projeto que se constrói coletivamente.Curitiba, 1995.

Avaliação Institucional na UFPR: trajetória de uma década 1987/ 1997. Curitiba: UFPR, 1998.

Planejamento, Universidade e Modernidade. Curitiba: AUGMAllGraf, 1998 
A Educação como as prioridades das prioridades. Curitiba: Champagnat, 1999. (Cadernos de Graduação).

ZAINKO, Maria Amélia S. O Planejamento como instrumento de Gestão educacional: uma análise histórico-filosófica. EM ABERTO, Brasília, v. 17, n. 72, p.125-140, 2000.

. Dos saberes às competências: o desafio da construção de um novo processo de formação. Revista Diálogo Educacional, Curitiba, v.2, n.4, 2001 . Educação Superior, Democracia e desenvolvimento humano Sustentável. In: _ Políticas e Gestão da Educação Superior. Curitiba: Champagnat, 2002

. Construindo a Nova Universidade. In: Políticas Públicas de Educação Superior: desafios e proposições. Brasília: FUNADESP, 2002

Recebido em: 11/11/02

Aprovado em: 30/11/02 